\title{
VARIÁVEIS FISIOLÓGICAS DE ANTÚRIO CULTIVADO SOB DIFERENTES MALHAS DE SOMBREAMENTO
}

\section{PHYSIOLOGICAL VARIABLES IN ANTHURIUM CULTIVATED UNDER DIFFERENT SHADING SCREEN}

\author{
Juliana Domingues LIMA ${ }^{1}$ \\ Edson Shigueaki NOMURA ${ }^{2}$ \\ Eduardo Jun FUZITANI ${ }^{3}$ \\ Silvia Helena MODENESE-GORLA DA SILVA ${ }^{4}$
}

\section{RESUMO}

Alteração na qualidade espectral da radiação pode ter efeito significativo no crescimento e desenvolvimento de uma cultura vegetal. $\mathrm{O}$ objetivo do presente trabalho foi avaliar o crescimento de Anthurium andraeanum cv. Apalai sob diferentes malhas de sombreamento. Para tal, mudas micropropagadas foram plantadas em canteiros sob quatro malhas (azul, vermelha, preta e termo-refletora) com $70 \%$ de sombreamento. O delineamento experimental foi em blocos casualizados, com quatro tratamentos e quatro repetições de quatro plantas. As avaliações foram conduzidas quando as inflorescências apresentaram padrão para comercialização. Valores mais altos de área foliar foram observados em plantas cultivadas sob malha preta, seguida de plantas cultivadas sob malha termo-refletora, vermelha e por último, azul. As diferenças na área foliar específica e na razão clorofila $a / b$ entre os tratamentos não foram significativas. O teor de clorofilas, a fluorescência máxima $\left(F_{m}\right)$ e a razão entre a fluorescência variável e máxima $\left(F_{v} / F_{m}\right)$ foram baixos sob malha azul e vermelha, enquanto a fluorescência inicial $\left(F_{o}\right)$ foi elevada. $O$ teor de clorofilas correlacionou-se positivamente com a razão $F_{v} / F_{m}(r), 96 ; R^{2} 0,95 ; P$ $<0,0001)$. A malha preta proporcionou a melhor condição para o crescimento.

Palavras-chave: Anthurium andraeanum; malha colorida; qualidade espectral da radiação; crescimento; pigmentos fotossintéticos; fluorescência.

\begin{abstract}
Change in the spectral quality radiation can have significant effect on the growth and development of a crop plant. The objective of the present research was to evaluate the growth and yield of Anthurium andraeanum cv. Apalai under different shading screens. For developing such research, micropopageted seedlings were planted in beds under four screens (blue, red, black and thermo-reflective) with $70 \%$ of shading. The experimental design was in complete block randomized, with four treatments and four repetitions. The evaluations were carried out when the inflorescences presented standard for marketing. Higher values of leaf area were observed in plants grown under screen black, followed by plants grown under thermoreflective screen, red screen, and finally, blue. Differences in specific leaf area and in the ratio of chlorophyll a/chlorophyll $b$ were no significant between treatments. Chlorophylls content, maximum fluorescence $\left(F_{m}\right)$ and the ratio of variable to maximum fluorescence $\left(F_{v} / F_{m}\right)$ were low under blue and red screen, while the initial fluorescence $\left(F_{o}\right)$ was high. The chlorophyll content correlated positively with $\mathrm{F}_{\mathrm{v}} / \mathrm{F}_{\mathrm{m}}\left(\mathrm{r} 0,96 ; \mathrm{R}^{2} 0,95 ; P<0,0001\right)$. The black screen provided the best condition for growth.

Key-words: Anthurium andraeanum; color screen; spectral quality radiation; growth; photosynthetic pigments;
\end{abstract} fluorescence.

\footnotetext{
${ }^{1}$ Engenheira Agrônoma, Campus Experimental de Registro, Universidade Estadual Paulista “Júlio de Mesquita Filho”,UNESP, Rua Nélson Brihi Badur, n. 430, Vila Tupy, Registro, São Paulo, Brasil. CEP 11.900-000. E-mail: judlima@registro.unesp.br . Autor para correspondência

2 Engenheiro Agrônomo, Pólo Vale do Ribeira, Agência Paulista de Tecnologia dos Agronegócios, APTA, Rod. Régis Bittencourt, BR-116, Km 460, CP. 122, Registro, São Paulo, Brasil, CEP 11900-000, E-mail: edsonnomura@apta.sp.gov.br.

${ }^{3}$ Engenheiro Agrônomo, Pólo Vale do Ribeira, Agência Paulista de Tecnologia dos Agronegócios, APTA, Rod. Régis Bittencourt, BR-116, Km 460, CP. 122, Registro, São Paulo, Brasil, CEP 11900-000, E-mail: edufuzitani@apta.sp.gov.br.

${ }^{4}$ Tecnóloga em Processamento de Dados, Professora Assistente, Campus Experimental de Registro, Universidade Estadual Paulista “Júlio de Mesquita Filho", UNESP, Rua Nélson Brihi Badur, n. 430, Vila Tupy, Registro - SP, Brasil. CEP 11.900-000. E-mail: silvia@registro.unesp.br.
} 
LIMA, J.D. et al. Variáveis fisiológicas de antúrio...

\section{INTRODUÇÃO}

Anthurium andraeanum Lindl (antúrio), espécie largamente utilizada na floricultura e paisagismo, pertence à família Araceae (monocotiledônea), que inclui mais de 100 gêneros e 1500 espécies, principalmente tropicais. Seu cultivo vem se expandindo cada vez mais no Estado de São Paulo, sobretudo no Vale do Ribeira, sendo estimada a existência de 1,7 milhões de plantas na região (Tombolato et al., 2002). Apesar da significativa importância econômica, a cultura na região carece de estudos que visem melhor desempenho em termos de produtividade $\mathrm{e}$ características comerciais.

A quantidade de luz no ambiente é um fator determinante para fotossíntese e crescimento das plantas. A qualidade da luz também desempenha um papel importante na morfogênese e fotossíntese (Saebo et al., 1995), influenciando o modo como a luz é absorvida pela clorofila (Tennessen et al., 1994).

O manejo da qualidade da luz pode ser feito por meio do uso de malhas de polietileno coloridas com diferentes níveis de sombreamento (Kittas et al., 1999). Outro tipo de malha capaz de alterar as propriedades da radiação luminosa é a termorefletora aluminizada que além de permitir controle de temperatura (Altafin, 2005), aumenta a reflexão da radiação. Assim, as diferentes propriedades que as malhas de sombreamento possuem alteram de alguma forma o microclima e, conseqüentemente, o metabolismo das plantas que estão sob a sua influência.

Diversas variáveis fisiológicas podem ser utilizadas para analisar as respostas do crescimento das plantas à qualidade da luz, como as medidas de crescimento, do teor de pigmentos fotossintéticos e da fluorescência, que em conjunto, podem demonstrar modificações na morfologia ou no aparelho fotossintético da planta.

Na produção comercial de inflorescências de antúrio no Vale do Ribeira tem sido utilizada malha com sombreamento variando de 70 a $80 \%$. Essa recomendação é seguida pelo fato do excesso de luz resultar em dano a flores e folhas, e até mesmo em morte da planta (Omar et al., 2004). Em relação à coloração, tem sido utilizada malha predominantemente preta. No entanto, estudos mostraram respostas diversas de plantas ornamentais às alterações na qualidade da luz (Meirelles et al., 2007; Melo \& Alvarenga, 2009), havendo inclusive indicações de efeitos benéficos no cultivo de antúrio em vaso (Kobayashi et al., 2006). Assim sendo, pelo exposto, objetivou-se neste trabalho avaliar 0 desenvolvimento de Anthurium andraeanum cv. Apalai sob diferentes malhas de sombreamento.

\section{MATERIAL E MÉTODOS}

O experimento foi realizado no sítio Oriente, localizado no município de Pariquera-Açu, SP. O material vegetal consistiu em plantas de Anthurium andraeanum cv. Apalai micropropagadas e aclimatadas, obtidas pelo programa de seleção do Instituto Agronômico de Campinas. O plantio foi realizado em agosto de 2004, em canteiros com 1,2 $\mathrm{m}$ de largura construídos sob viveiro de $3,0 \mathrm{~m}$ de pé-direito coberto com diferentes malhas de sombreamento. Na ocasião do plantio, as plantas apresentavam cerca de $20 \mathrm{~cm}$ de altura. A adubação de plantio seguiu a análise de solo e a recomendação proposta por Raij et al. (1997), sendo aplicados $50 \mathrm{~g} \mathrm{~m}^{-2}$ de termofosfato e 0,004 $\mathrm{m}^{3} \mathrm{~m}^{-2}$ de esterco de curral curtido. A adubação de produção consistiu na aplicação de $50 \mathrm{~g} \mathrm{~m}^{-2}$ do adubo NPK formulação 10-10-10 a cada dois meses durante o período de maior desenvolvimento das plantas (verão). Foi feita também a distribuição 0,02 $\mathrm{m}^{3} \mathrm{~m}^{-2}$ de serragem na superfície dos canteiros para manter a umidade do solo e diminuir a incidência de plantas daninhas. Periodicamente, após a colheita das hastes florais, a folha mais velha da planta foi removida, mantendo-se quatro folhas por planta.

O delineamento experimental foi inteiramente casualizado com quatro tratamentos e quatro repetições. As parcelas foram constituídas de quatro plantas, considerando-se, para análise dos dados, a média dessas quatro plantas. Os tratamentos consistiram em quatro malhas de sombreamento: azul (ChromatiNet ${ }^{\circledR}$ Azul 70\%); vermelha (ChromatiNet ${ }^{\circledR}$ Vermelha $70 \%$ ); preta (Malha preta $70 \%$ ) e termo-refletora (Aluminet $70 \%)$.

Os elementos do clima durante a condução do experimento estão apresentados na Figura 1. As avaliações foram realizadas em plantas adultas, no 32 - mês após o plantio.

As variáveis analisadas foram: altura da planta, comprimento do pecíolo, comprimento máximo e largura máxima da folha, área foliar, a área foliar específica, teores de clorofilas e carotenóides, e características da cinética de emissão da fluorescência rápida. Altura da planta (AP) obtida a partir do nível do solo até a inserção da última folha completamente expandida $(\mathrm{cm})$; comprimento do pecíolo foliar (CP) medida do ponto de inserção da folha no caule até o ponto de contato com o limbo foliar $(\mathrm{cm})$; comprimento máximo da folha $(C)$ medida da base ao ápice do limbo foliar $(\mathrm{cm})$; largura máxima da folha (L) medida aproximadamente no meio do limbo foliar $(\mathrm{cm})$; a área foliar (AF) determinada por meio da equação de regressão $\mathrm{AF}=0,9672 \times \mathrm{CxL}$, proposta por Modenese-Gorla da Silva et al. (2008); a área foliar específica (AFE) determinada por meio da relação entre área e a massa da matéria seca $\left(\mathrm{cm}^{2}\right.$ $\mathrm{g}^{-1}$ ) de um disco foliar, retirado do limbo foliar da folha mais jovem completamente expandida.

As características da cinética de emissão da fluorescência rápida foram determinadas por meio de um fluorômetro portátil (Handy-PEA, Hansatech, Norfolk, England). As medições foram feitas na folha mais jovem completamente expandida, previamente adaptada a 30 min de obscuridade, a fim de promover a abertura de todos os centros de reação do fotossistema II. Em seguida, as folhas foram expostas a um pulso de luz de $700 \mu \mathrm{mol} \mathrm{m} \mathrm{m}^{-2}$ 
$\mathrm{s}^{-1}$ por $5 \mathrm{~s}$. As fluorescências inicial $\left(\mathrm{F}_{\mathrm{o}}\right)$, variável $\left(F_{v}\right)$ e máxima $\left(F_{m}\right)$ e a razão entre a fluorescência variável e máxima $\left(F_{v} / F_{m}\right)$ foram calculadas automaticamente pelo equipamento.

$\mathrm{O}$ teor de clorofila $a(\mathrm{Cl} a)$ e $b(\mathrm{Cl} b)$ e carotenóides (Car) foi determinado também em discos foliares coletados da folha mais jovem e completamente expandida. Os discos foram imersos em 7,0 $\mathrm{cm}^{3}$ de dimetil-sulfóxido (DMSO) e incubados por $30 \mathrm{~min}$ a $70^{\circ} \mathrm{C}$, no escuro (Hiscox \& Israelstam, 1979). Após o resfriamento foram adicionados mais $3,0 \mathrm{~cm}^{3}$ de DMSO, perfazendo um volume final de $10 \mathrm{~cm}^{3}$. As absorbâncias das soluções resultantes foram medidas em espectrofotômetro a 480, 649 e $665 \mathrm{~nm}$. Os teores de pigmentos foram estimados a partir das equações propostas por Wellburn (1994):

$\left[\mathrm{Cl}\right.$ a] $\left(\mu \mathrm{g} \mathrm{cm}^{-3}\right)=12,19 A_{665}-3,45 A_{649}$;

$[\mathrm{Cl} b]\left(\mu \mathrm{g} \mathrm{cm}^{-3}\right)=21,99 A_{649}-5,32 A_{665}$;

[Car] $\left(\mu \mathrm{g} \mathrm{cm}^{-3}\right)=\left\{\left[\left(1000 A_{480}-2,14\right.\right.\right.$ Clorofila a $70,16$ Clorofila $b) * 10] / 220 \times M\}$.

Onde $A$ é a absorbância medida em espectrofotômetro e $M$ é a massa da matéria fresca utilizada na extração.

Os dados foram submetidos à análise de variância pelo teste $\mathrm{F}$, e as médias dos tratamentos foram comparadas a $5 \%$ de probabilidade pelo teste de Tukey. As correlações foram realizadas pelo método de Pearson, usando o teste t no programa SAEG (Ribeiro Júnior, 2001).

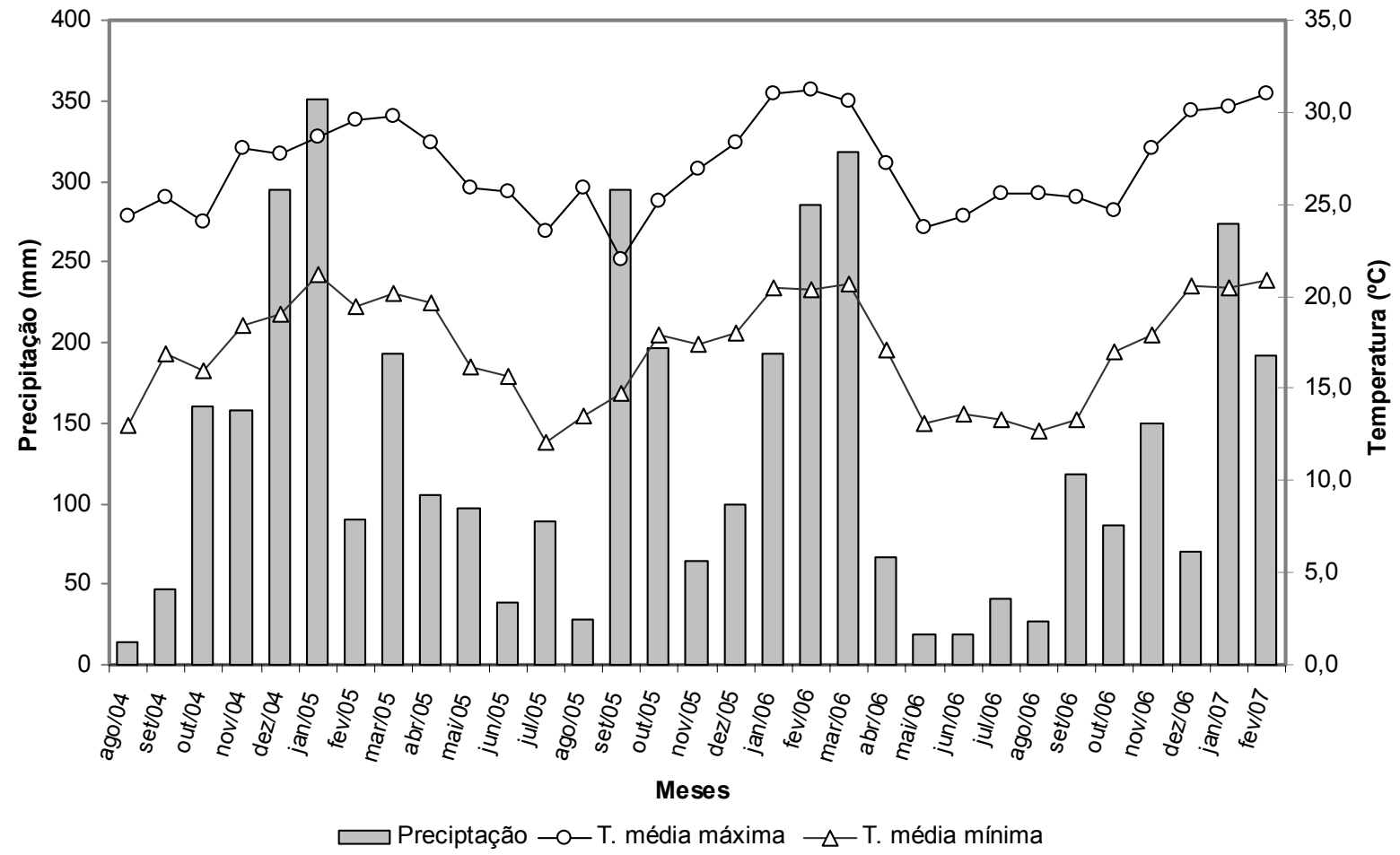

FIGURA 1 - Elementos do clima durante a condução do experimento em Pariquera-Açu, SP.

\section{RESULTADOS E DISCUSSÃO}

Para altura da planta (AP), comprimento do pecíolo $(C P)$, comprimento $(C)$ e largura $(L)$ da folha e área foliar (AF), a melhor resposta em termos de crescimento foi apresentada pelas plantas cultivadas sob malha preta, diferindo das plantas cultivadas sob as demais malhas de sombreamento (Tabela 1).

Em conjunto, as diferenças no comprimento (C) e na largura da folha (L) resultantes do uso de diferentes malhas refletiram-se na área foliar total
(AF) das plantas, de tal maneira que plantas sob as malhas vermelha e azul exibiram os menores valores de área foliar (Tabela 1). Contudo, plantas de Melissa officinalis não apresentaram diferenças na área foliar quando cultivadas sob malhas azul, preta e vermelha (Brant et al., 2009), enquanto plantas de Dracaena marginata 'Colorama' cultivadas sob malha vermelha apresentaram valores mais altos, em relação às malhas preta, azul e cinza (Kawabata et al., 2007).

Apesar das diferenças na área foliar total (AF) das plantas de antúrio, não houve diferenças 
LIMA, J.D. et al. Variáveis fisiológicas de antúrio...

na área foliar específica (AFE) (Tabela 1), que relaciona a superfície da folha, componente morfológico, com a massa da matéria seca da folha, componente anatômico (Benincasa, 2003). Isso significa que o padrão de acúmulo de compostos orgânicos na folha foi igualmente acompanhado pela expansão da área foliar em todos os tratamentos, e que não houve alterações na espessura da folha. Resultado semelhante foi obtido por Lee et al. (2000). Segundo os mesmos, a espessura da folha é afetada apenas pela intensidade luminosa, sendo a qualidade espectral da luz incapaz de afetar a contribuição das camadas de tecido no espessamento total da folha e composição do mesófilo. Também não foram observadas alterações na espessura do limbo foliar em plantas de Ocimum selloi (Costa et al., 2007) e Ocimum gratissimum (Martins et al., 2009) cultivadas sob malha vermelha e azul e de Mikania laevigata (Souza et al., 2007) cultivada sob malha vermelha, azul e preta, em todos os casos com $50 \%$ de sombreamento.

TABELA 1 - Altura da planta (AP), comprimento do pecíolo (CP), comprimento (C) e largura (L) máximo médio da folha, área foliar total (AF) e área foliar específica (AFE) de plantas de Anthurium andraeanum cv. Apalai cultivadas sob diferentes malhas de sombreamento. Pariquera-Açu/SP, 2007.

\begin{tabular}{lllllll}
\hline Malhas & $\begin{array}{l}\mathrm{AP} \\
\mathrm{cm}\end{array}$ & $\begin{array}{l}\mathrm{CP} \\
\mathrm{cm}\end{array}$ & $\begin{array}{l}\mathrm{C} \\
\mathrm{cm}\end{array}$ & $\begin{array}{l}\mathrm{L} \\
\mathrm{cm}\end{array}$ & $\begin{array}{l}\mathrm{AF} \\
\mathrm{cm}^{2} \mathrm{planta}^{-1}\end{array}$ & $\begin{array}{l}\text { AFE } \\
\mathrm{cm}^{2} \mathrm{~g}^{-1}\end{array}$ \\
\hline Preta & $89,20 \mathrm{a}$ & $31,49 \mathrm{a}$ & $21,79 \mathrm{a}$ & $16,72 \mathrm{a}$ & $1.371,72 \mathrm{a}$ & 62,38 \\
Termo-refletora & $75,29 \mathrm{~b}$ & $24,21 \mathrm{~b}$ & $18,98 \mathrm{~b}$ & $14,63 \mathrm{~b}$ & $1.099,57 \mathrm{~b}$ & 61,41 \\
Vermelha & $60,76 \mathrm{~b}$ & $20,91 \mathrm{bc}$ & $17,32 \mathrm{bc}$ & $12,99 \mathrm{bc}$ & $868,85 \mathrm{bc}$ & 63,37 \\
Azul & $56,92 \mathrm{~b}$ & $20,00 \mathrm{c}$ & $16,85 \mathrm{c}$ & $12,35 \mathrm{c}$ & $806,23 \mathrm{c}$ & 66,33 \\
Média geral & 70,54 & 24,16 & 18,73 & 14,17 & 1041,51 & 62,62 \\
CV (\%) & 5,25 & 7,75 & 5,27 & 5,78 & 6,57 & 5,09 \\
F & $63,42 * *$ & $30,99^{* *}$ & $20,44 * *$ & $22,71 * *$ & $64,06 * *$ & $0,34{ }^{\mathrm{ns}}$ \\
DMS & 7,33 & 3,93 & 2,07 & 1,72 & 143,61 & 6,69 \\
\hline
\end{tabular}

Médias seguidas da mesma letra não diferem entre si, a $5 \%$ de probabilidade pelo teste Tukey. ns - não significativo.

${ }^{* *} e^{*}$ - significativo a 1 e $5 \%$ de probabilidade, respectivamente.

Teores mais altos de clorofilas totais $(\mathrm{Cl}$ tot), e de clorofilas a $(\mathrm{Cl} a)$ e $b(\mathrm{Cl} b)$ foram observados em plantas cultivadas sob malha preta, seguidos de plantas cultivadas em malha termo-refletora e, por último, das malhas vermelha e azul, que não diferiram entre si (Tabela 2). Contrariamente, Cattleya walkeriana (Dignart, 2006) e Azorina vidalii (Silva \& Debergh, 1997) não apresentaram diferenças no teor de clorofila a sob radiação artificial enriquecida com luz azul, porém em radiação enriquecida com luz vermelha, ocorreu diminuição deste pigmento. Plantas de Catharanthus roseus cv. 'Pacifica White' também exibiram teor de clorofila a mais elevado sob malha azul e preta quando comparado com a malha vermelha (Melo \& Alvarenga, 2009). Contudo, Pittosporum variegatum não apresentou diferenças no teor de clorofilas em plantas mantidas sob malhas cinza, preta, termo-refletora, vermelha, verde e azul (Oren-Shamir et al., 2001).
Os teores de carotenóides (Car) nas folhas foram mais elevados sob malha preta, não diferindo entre plantas cultivadas sob os demais tipos de malha (Tabela 2). Gussakovsky et al. (2007) não observaram diferenças no teor de carotenóides de folhas de ervilha durante a fase de crescimento sob diferentes colorações de iluminação.

Não houve diferenças na razão clorofila $a / b(\mathrm{Cl} a / b)$ entre os tratamentos (Tabela 2). Plantas de Dendranthema grandiflora aclimatadas sob malhas preta, vermelha e azul também não apresentaram diferenças nessa razão (Braga, 2006), assim como mudas de bananeira aclimatizadas sob malha preta e termo-refletora (Altafin, 2005). Contudo, a razão clorofila/ carotenóides (Cl/Car) foi mais elevada nos tratamentos com malhas termo-refletora e preta em relação aos demais (Tabela 2 ), cuja alteração pode ser explicada tanto por diferenças no teor de clorofilas totais quanto de carotenóides. 
LIMA, J.D. et al. Variáveis fisiológicas de antúrio...

TABELA 2 - Teor de clorofila a $(\mathrm{Cl} a)$, clorofila $b(\mathrm{Cl} b)$, clorofilas totais ( $\mathrm{Cl}$ tot) e carotenóides (Car), razão clorofila a/b $(\mathrm{Cl} a / b)$ e razão clorofilas/carotenóides (Cl/Car) em folhas de Anthurium andraeanum cv. Apalai cultivadas sob diferentes malhas de sombreamento. Pariquera-Açu/SP, 2007.

\begin{tabular}{lllllll}
\hline Malhas & $\mathrm{Cla}$ & $\mathrm{Cl} b$ & $\mathrm{Cl}$ tot & $\mathrm{Car}$ & $\mathrm{Cl} \mathrm{a/b}$ & $\mathrm{Cl} / \mathrm{Car}$ \\
& $\mu \mathrm{g} \mathrm{cm}^{-3}$ & $\mu \mathrm{g} \mathrm{cm}^{-3}$ & $\mu \mathrm{g} \mathrm{cm}^{-3}$ & $\mu \mathrm{g} \mathrm{cm}^{-3}$ & & \\
\hline Preta & $0,983 \mathrm{a}$ & $0,653 \mathrm{a}$ & $1,635 \mathrm{a}$ & $0,323 \mathrm{a}$ & 1,507 & $5,079 \mathrm{a}$ \\
Termo-refletora & $0,835 \mathrm{~b}$ & $0,605 \mathrm{~b}$ & $1,440 \mathrm{~b}$ & $0,275 \mathrm{~b}$ & 1,382 & $5,257 \mathrm{a}$ \\
Azul & $0,645 \mathrm{c}$ & $0,450 \mathrm{c}$ & $1,095 \mathrm{c}$ & $0,286 \mathrm{ab}$ & 1,434 & $3,857 \mathrm{~b}$ \\
Vermelha & $0,650 \mathrm{c}$ & $0,453 \mathrm{c}$ & $1,104 \mathrm{c}$ & $0,265 \mathrm{~b}$ & 1,433 & $4,180 \mathrm{~b}$ \\
Média geral & 0,778 & 0,540 & 1,319 & 0,287 & 1,434 & 4,593 \\
CV (\%) & 3,87 & 2,59 & 2,15 & 7,23 & 4,89 & 7,48 \\
F & $116,4{ }^{* *}$ & $221,32 * *$ & $347,40^{* *}$ & $5,86 *$ & 2,13 & 15,71 * \\
DMS & 0,063 & 0,029 & 0,060 & 0,044 & 0,148 & 0,721 \\
\hline
\end{tabular}

Médias seguidas da mesma letra não diferem entre si, a $5 \%$ de probabilidade pelo teste Tukey. ns - não significativo.

${ }^{* *} e^{*}$ - significativo a 1 e $5 \%$ de probabilidade, respectivamente.

$\mathrm{Na}$ fotossíntese a luz é absorvida por pigmentos do complexo-antena, que quando excitados, transferem energia para os centros de reação dos fotossistemas I e II (Young \& Frank, 1996). Quando ocorre excesso de energia, esta pode ser dissipada na forma de fluorescência (Krause \& Winter, 1996). Uma das formas de monitoramento da inibição ou redução na transferência de elétrons entre os fotossistemas da planta sob estresse é a fluorescência da clorofila a (Bolhár-Nordenkampf \& Öquist, 1993), uma vez que a redução na dissipação da energia pelo processo fotoquímico é refletida por incremento correspondente na fluorescência (Catunda et al., 2005). Os valores das fluorescências inicial $\left(F_{0}\right)$ e máxima $\left(F_{m}\right)$ e da razão entre as fluorescências variável e máxima $\left(F_{v} / F_{m}\right)$ são obtidos na "fase rápida" da cinética de emissão de fluorescência (Bolhár-Nordenkampf \& Öquist, 1993). Alterações observadas nestes parâmetros podem indicar variações na capacidade fotossintética da planta.

Valores mais altos de $F_{\circ}$ indicam destruição do centro de reação do FSII ou diminuição na capacidade de transferência da energia de excitação do sistema antena para o centro de reação (Baker \& Rosenqvst, 2004) (Tabela 3). Os valores mais baixos de $F_{m}$ nas plantas sob malhas azul e vermelha quando comparadas com plantas cultivadas sob malhas termo-refletora e preta, podem indicar diminuição na velocidade de reoxidação das plastoquinonas reduzidas, devida à redução na transferência de elétrons para o fotossistema I e ao menor consumo de poder redutor (NADPH $+\mathrm{H}^{+}$) durante a fixação do $\mathrm{CO}_{2}$ (Krause \& Weis, 1991). As reduções em $F_{v}$ e $F_{v} / F_{m}$ nas plantas dos mesmos tratamentos indicam diminuição na eficiência fotoquímica do fotossistema II (Krause \& Weis, 1991).

TABELA 3 - Fluorescências inicial $\left(F_{o}\right)$, variável $\left(F_{v}\right)$ e máxima $\left(F_{m}\right)$ e a razão entre as fluorescências variável e máxima $\left(\mathrm{F}_{\mathrm{v}} / \mathrm{F}_{\mathrm{m}}\right)$ de plantas de Anthurium andraeanum cv. Apalai cultivadas sob diferentes malhas de sombreamento. Pariquera-Açu/SP, 2007.

\begin{tabular}{lllll}
\hline Malhas & $\mathrm{F}_{\mathrm{o}}$ & $\mathrm{F}_{\mathrm{v}}$ & $\mathrm{F}_{\mathrm{m}}$ & $\mathrm{F}_{\mathrm{v}} / \mathrm{F}_{\mathrm{m}}$ \\
\hline Preta & $609 \mathrm{c}$ & $2.700 \mathrm{a}$ & $3.309 \mathrm{a}$ & $0,816 \mathrm{a}$ \\
Termo-refletora & $606 \mathrm{c}$ & $2.718 \mathrm{a}$ & $3.324 \mathrm{a}$ & $0,818 \mathrm{a}$ \\
Azul & $658 \mathrm{a}$ & $2.140 \mathrm{~b}$ & $2.795 \mathrm{~b}$ & $0,765 \mathrm{~b}$ \\
Vermelha & $643 \mathrm{~b}$ & $2.162 \mathrm{~b}$ & $2.806 \mathrm{~b}$ & $0,770 \mathrm{~b}$ \\
Média geral & 629 & $2.429,81$ & 3058 & 0,792 \\
CV (\%) & 1,09 & 6,67 & 9,90 & 7,90 \\
F & $55,73 * *$ & $1.624,02 * *$ & $464,55^{* *}$ & $83,62^{* *}$ \\
DMS & 14,36 & 33,62 & 58,10 & 0,013
\end{tabular}

Médias seguidas da mesma letra não diferem entre si, a $5 \%$ de probabilidade pelo teste Tukey.

ns - não significativo. ${ }^{* *} \mathrm{e}^{*}$ - significativo a 1 e $5 \%$ de probabilidade, respectivamente

Scientia Agraria, Curitiba, v.11, n.3, p.193-200, May/Jun. 2010. 
LIMA, J.D. et al. Variáveis fisiológicas de antúrio...

A análise da correlação entre teores de clorofilas totais e razão $F_{v} / F_{m}$, mostra que a correlação foi fortemente positiva (Figura 2A), enquanto a correlação entre teor de carotenóides e razão $F_{v} / F_{m}$ foi positiva (Figura $2 B$ ), porém fraca. Assim, quanto maior o teor de clorofilas maior a eficiência fotossintética, independente do tipo de malha de sombreamento. Apesar de não ter sido observada diferença na razão $F_{v} / F_{m}$ entre plantas cultivadas nas malhas preta e termo-refletora
(Tabela 3), os teores de pigmentos (Tabela 2) e a maioria das variáveis do crescimento (Tabela 1) foram superiores sob malha preta, quando comparada com a malha termo-refletora. Isso demonstra que a eficiência fotossintética mais elevada detectada em plantas sob malha termorefeletora não se traduziu em melhor desempenho em termos de crescimento, provavelmente pelo microclima gerado pela malha termo-refletora.

\section{A}
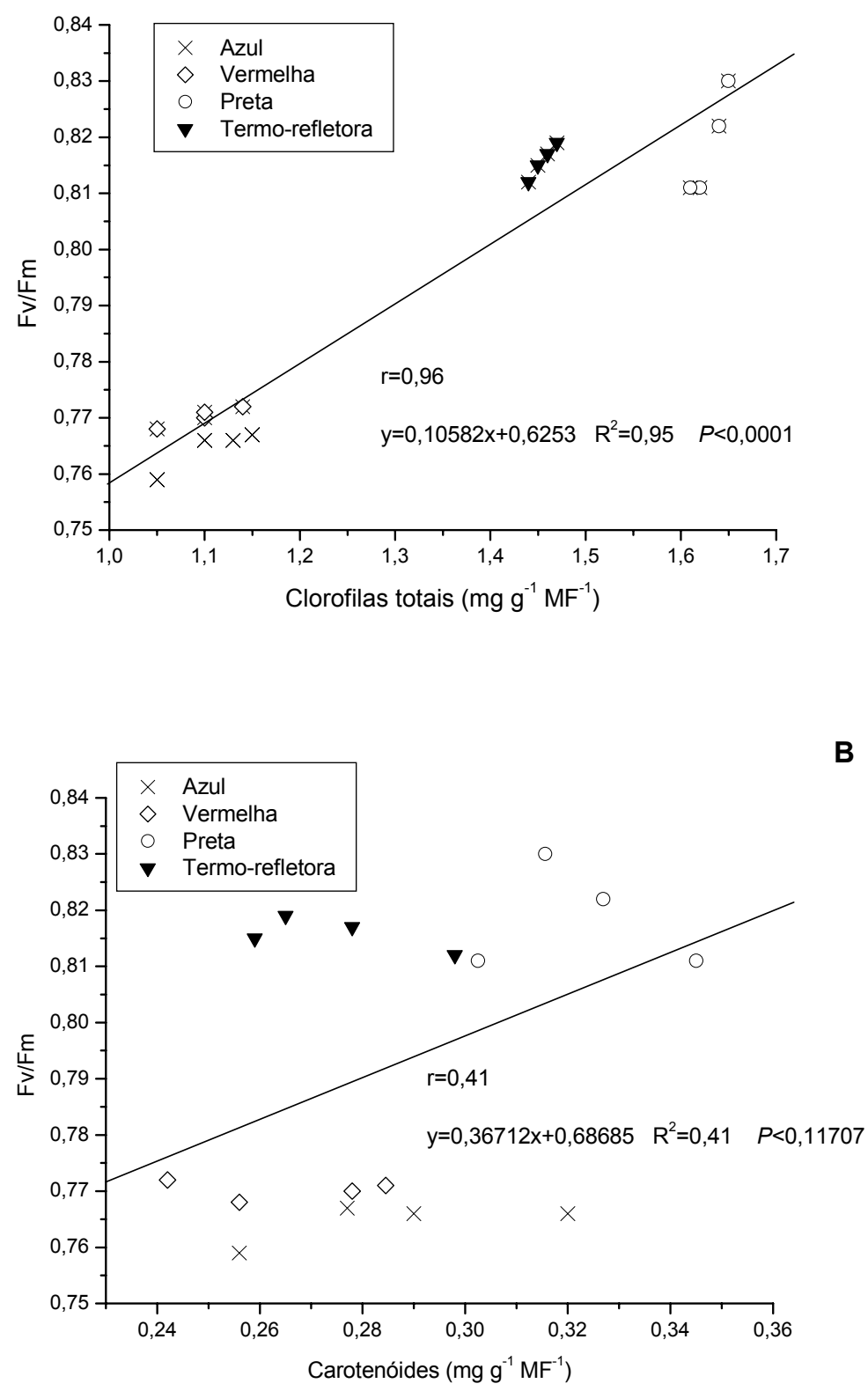

FIGURA 2 - Correlação entre o teor de clorofilas totais (A) e carotenóides (B) e a eficiência fotoquímica do fotossistema II (FV/FM) em folhas de Anthurium andraeanum cV. Apalai cultivadas sob diferentes malhas de sombreamento. Pariquera-Açu/SP, 2007. $r=$ coeficiente de correlação; $R^{2}=$ coeficiente de determinação da equação de regressão. 
LIMA, J.D. et al. Variáveis fisiológicas de antúrio...

Percebe-se que as malhas azul e vermelha não propiciaram condição ambiental adequada para o crescimento do antúrio. Segundo Oren-Shamir et al. (2001), o espectro típico da malha azul apresenta um pico principal de transmitância na região do azul-verde (400-540 nm), enquanto a tela vermelha possui maior transmitância além de 590 $\mathrm{nm}$. A propriedade mais importante desses tipos de tela é alteração da razão azul:vermelho $(A: V)$, sem alterações significativas na razão vermelho:vermelho distante (V:VD) (Gussakovsky et al., 2007). Para algumas plantas, a luz vermelha tem influência no desenvolvimento, promovendo maior alongamento do caule e florescimento, bem como alterações na condutância estomática. Para a luz azul tem sido descrita respostas relacionadas ao processo de síntese de pigmentos e enzimas, à abertura e fechamento dos estômatos e aos processos fotomorfogênicos (Schuerger et al., 1997). Todavia, nas condições testadas, a malha azul e vermelha, onde a luz que passa possui um poder de radiação maior (Braga, 2006), pelo fato de aumentar a disponibilidade de radiação de comprimento de onda com efeito na fotossíntese, ocorreram mudanças negativas no ambiente de cultivo das plantas, que se refletiram no teor de pigmentos (Tabela 2) e parâmetros da fluorescência (Tabela 3). Essas alterações, em conjunto, reduziram a capacidade fotossintética e, como conseqüência, o crescimento (Tabela 1), o que provavelmente resultará numa redução do potencial produtivo das plantas.

O excesso de luz pode afetar a fotossíntese por meio de dois processos: a foto-oxidação e a foto-inibição. Segundo Streit et al. (2005), a fotooxidação é um processo irreversível e envolve diretamente os pigmentos receptores de luz, os quais, ao absorverem muita luz, ficam muito tempo excitados, interagem com $\mathrm{O}_{2}$ e formam radicais livres como o superóxido. Esses radicais são prejudiciais aos pigmentos fotossintéticos. A fotoinibição envolve danos aos fotossistemas, especialmente ao Fotossistema II. No Fotossistema II ocorre perda da proteína D1 envolvida na transferência de elétrons do Fotossintema II à plastoquinona, que pode ser recuperada posteriormente.

Segundo Hendry \& Price (1993), a relação entre as clorofilas e carotenóides (Cl/Car) pode ser usada como um indicador potencial de perdas fotooxidativas causadas por forte radiação, pelo fato dos carotenóides poderem prevenir a foto-oxidação das clorofilas. Como o teor de carotenóides (Car) nas plantas sob malha azul e vermelha não foi superior ao das plantas cultivadas sob malha preta e termo-refletora (Tabela 2), a acumulação de carotenóides parece não ter sido a estratégia utilizada para proteção de danos por luz, detectado pelas alterações em $F_{o}$ e $F_{m}$. (Tabela 3 )

\section{CONCLUSÃO}

Nas condições em que o presente estudo foi realizado, observou-se que a malha preta com $70 \%$ de sombreamento proporciona a melhor condição para o crescimento de plantas de antúrio, o que provavelmente permitirá maior produção de hastes florais.

\section{REFERÊNCIAS}

1. ALTAFIN, V. L. Estudo da micropropagação, aclimatação e econômico prévio do plantio em campo de Musa spp. 2005. 78 f. Tese (Doutorado em Ciências Biológicas) - Curso de Pós-graduação em Ciências Biológicas, Universidade Estadual Paulista, Rio Claro.

2. BAKER, N. R.; ROSENQVST, E. Applications of chlorophyll fluorescence can improve crop production strategies: an examination of future possibilities. Journal of Experimental Botany, v. 55, n. 403, p.1607-1621, 2004.

3. BENINCASA, M. M. P. Análise de crescimento de plantas: noções básicas. Jaboticabal: FUNEP, 2003. 41p.

4. BOLHÁR-NORDENKAMPF, H. R.; ÖQUIST, G. Chlorophyll fluorescence as a tool in photosynthesis research. In: HALL, D. O. et al. (Ed.). 1. ed. Photosynthesis and production in changing environment: a field and laboratory manual. London: Chapman \& Hall, 1993. p.193-206.

5. BRAGA, F. T. Ambiente de cultivo na propagação in vitro de Crisântemo (Dendranthema grandiflora Tzvelev cv. Rage): características anatômicas e fisiológicas. 2006. 119 f. Dissertação (Mestrado em Fisiologia Vegetal) Universidade Federal de Lavras, Lavras.

6. BRANT, R. da S. et al. Crescimento, teor e composição do óleo essencial de melissa cultivada sob malhas fotoconversoras. Ciência Rural, v. 39, n. 5, p. 1401-1407, 2009.

7. CATUNDA et al. Efeitos de herbicidas na atividade fotossintética e no crescimento de abacaxi (Ananas comossus). Planta Daninha, v. 23, n. 1, p. 115-121, 2005.

8. COSTA, L. C. do B. et al. Aspectos da anatomia foliar de Ocimum selloi Benth. (Lamiaceae) em diferentes condições de qualidade de luz. Revista Brasileira de Biociências, v. 5, n. 1, p. 6-8, 2007.

9. DIGNART, S. L. Luz e sacarose na micropropagação de Cattleya walkeriana: alterações anatômicas e fisiológicas. 2006. 138 p. Dissertação (Mestrado em Agronomia/Fisiologia Vegetal) - Universidade Federal de Lavras, Lavras.

10. GUSSAKOVSKY E. E. et al. Color of illumination during growth affects LHCII chiral macroaggregates in pea plant leaves. Journal of Photochemistry and Photobiolog B: Biology, v. 86, n. 2, p.121-130, 2007.

11. HENDRY, G. A. F.; PRICE, A. H. Stress indicators: chlorophylls and carotenoids. In: HENDRY, G. A. F.; GRIME, J. P. (Ed.) Methods in comparative plant ecology: A laboratory manual. London: Chapman \& Hall, 1993. p. 148-152.

12. HISCOX, J. D.; ISRAELSTAM, G. F. A method for the extraction of chlorophyll from leaf tissue without maceration. Canadian Journal of Botany, v. 57, n. 12, p. 1332-1334, 1979.

13. KAWABATA, A. F. et al. Effects of photoselective shade cloths on potted Dracaena deremensis 'Janet Craig' and Dracaena marginata 'Colorama'. Journal of Hawaiian and Pacific Agriculture, v. 14, p. 49-54, 2007.

14. KITTAS, C.; BAILLE, A.; GIAGLARAS, P. Influence of covering material and shading on the spectral distribution of light in greenhouses. Journal of Agricultural Engineering Research, v. 73, n. 4, p. 341-351, 1999 
LIMA, J.D. et al. Variáveis fisiológicas de antúrio...

15. KOBAYASHI, K. D. et al. Effects of photoselective shadecloths on potted Dracaena and Anthurium plants. HortScience, v. 41, n. 4, p. 1053-1054, 2006

16. KRAUSE, G. H.; WEIS, E. Chlorophyll fluorescence and photosynthesis: The basics. Annual Review of Plant Physiology and Plant Molecular Biology, v. 42, p. 313-349, 1991.

17. KRAUSE, G. H.; WINTER, K. Photoinhibition of photosynthesis in plants growing in natural tropical forest gaps: a chlorophyll fluorescence study. Botanica Acta, v. 109, n. 6, p. 456-462, 1996.

18. LEE, D. W. et al. Effects of irradiance and spectral quality on leaf structure and function in seedlings of two Southeast Asian Hopea (Dipterocarpaceae) species. American Journal of Botany, v. 87, n. 4, p. 447-455, 2000

19. MARTINS, J. R. et al. Anatomia foliar de plantas de alfavaca-cravo cultivadas sob malhas coloridas. Ciência Rural, v. 39 , n. 1, p. 82-87, 2009.

20. MEIRELLES, A. J. A. et al. Influência de diferentes sombreamentos e nutrição foliar no desenvolvimento de mudas de palmeira ráfia Rhapis excelsa (Thunberg) Henry ex. Rehder. Ciência e Agrotecnologia, v. 31, n. 6, p. 1884-1887, 2007.

21. MELO, A. A. M.; ALVARENGA, A. A. de. Sombreamento de plantas de Catharanthus roseus (L.) G. Don 'Pacifica White' por malhas coloridas: desenvolvimento vegetativo. Ciência e Agrotecnologia, v. 33, n. 2, p. 514-520, 2009.

22. MODENESE-GORLA DA SILVA, S. H. et al. Estimativa da área foliar do antúrio com o uso de funções de regressão. Ciência Rural, v. 38, n. 1, p. 243-246, 2008.

23. OMAR, M. H. et al. For market access on Anthurium. Kuala Lumpur: Crop Protection \& Plant Quarentine Services Division, Department of Agriculture, 2004. 44 p. (Technical Document)

24. OREN-SHAMIR, M. et al. Colored shade nets can improve the yield and quality of green decorative branches of Pittosporum variegatum. Journal of Horticultural Science and Biotechnology, v. 76, n. 3, p. 353-361, 2001.

25. RAIJ, B. V. et al. Recomendação de adubação e calagem para o Estado de São Paulo. 2. ed. Campinas: FUNDAG 1997. 285 p. (Boletim Técnico, 100)

26. RIBEIRO JÚNIOR, J. I. Análises estatísticas no SAEG. Viçosa: UFV, 2001. 301 p.

27. SAEBO, A.; KREKLING, T.; APPELGREN, M. Light quality affects photosynthesis and leaf anatomy of birch plantlets in vitro. Plant Cell, Tissue and Organ Culture, v. 41, n. 2, p.177-185, 1995.

28. SOUZA, G. S. de et al. Estrutura foliar e de cloroplastídeos de Mikania laevigata Schultz Bip. ex Baker em diferentes condições de qualidade de luz. Revista Brasileira de Biociências, v. 5, supl.1, p. 78-80, 2007.

29. SCHUERGER, A. C.; BROWN, C.; STRYJEWSKI, E. C. Anatomical features of pepper plants (Capsicum annuum L.) growth under red light emitting diodes supplemented with blue or far-red light. Annals of Botany, v. 79 , n. 3, p. 273-282, 1997.

30. SILVA, M. H. M. da; DEBERGH, P. C. The effect of light quality on the morphogenesis of in vitro cultures of Azorina vidalii (Wats.) Feer. Plant Cell, Tissue and Organ Culture, v. 51, n. 3, p. 187-193, 1997.

31. STREIT, N. M. et al. As clorofilas. Ciência Rural, v. 35, n. 3, p. 748-755, 2005.

32. TENNESSEN, D. J.; SINGSAAS, E. L.; SHARKEY, T. D. Light-emitting diodes as a light source for photosynthesis research. Photosynthesis Research, v. 39, n. 1, p. 85-92, 1994.

33. TOMBOLATO, A. F. C. et al. O cultivo de antúrio: produção comercial. Campinas: Instituto Agronômico, 2002.47 p. (Série Tecnológica APTA, Boletim Técnico IAC, 194)

34. WELLBURN, A. R. The spectral determination of chlorophyll a and $b$, as well as total carotenoids, using various solvents with spectrophotometers of different resolution. Journal of Plant Physiology, v. 144, n. 3, p. 307-313, 1994.

35. YOUNG, A. L.; FRANK, H. A. Energy transfer reactions involving carotenoids: quenching of chlorophyll fluorescence. Journal of Photochemistry and Photobiolog B: Biology, v. 36, n. 1, p. 3-15, 1996.

Recebido em 12/03/2009

Aceito em $07 / 01 / 2010$ 